Case Report

\title{
Effectiveness of prenatal intensive counselling on knowledge, attitude and acceptance of post placental intrauterine contraceptive device among mothers
}

\author{
M Shanthini ${ }^{1}$, Manjubala Dash ${ }^{2 *}$, A Felicia Chitra ${ }^{3}$, S Jayanthi ${ }^{4}$ \\ and P Sujatha ${ }^{5}$
}

'Department of Nursing, India

${ }^{2}$ Department OBG, MTPG \& RIHS, Puducherry, India

${ }^{3}$ Principal, HOD, Department of MSN

${ }^{4}$ Dean , MTPG \& RIHS, Puducherry, India

${ }^{5}$ Medical Superintendent, RGGWCH, Puducherry, India

\section{Abstract}

Introduction: Contraception is a method or device used to prevent pregnancy. In the first year of postpartum period around $65 \%$ of women are having unmet need of family planning. Post Placental Intrauterine Contraceptive Device is not only advantageous to the women and couples; even the service providers benefit from PPIUCD. PPIUCD insertion on the same delivery table saves time and separate clinical procedure is not required.

Methodology: The Quantitiative Pre-Experimental One Group Pre and Post Test research design was used. 70 Antenatal mothers were selected by using Purposive Sampling Technique who fulfilled the inclusion criteria and who were available during the period of data collection at selected hospital, Puducherrry. Data was collected by using Structured Interview Schedule.

Result: The Pre test mean score of Knowledge was $9.98 \pm 2.38$ and Post Test mean score of Knowledge was $14.91 \pm 1.15$. The calculated paired' $t$ ' value was $(-20.82)$ found to be statistically significant at $p<0.001$ level. The Pretest mean score of Attitude was $34.67 \pm 5.67$ and Post test mean score of Attitude was $44.27 \pm 4.70$. The calculated paired't' value was $(-17.25)$ found to be statistically significant at $p<0.001$ level. The Pretest mean score of Acceptance was $0.11 \pm$ 0.320 and Post Test mean score of Acceptance was $0.29 \pm 0.455$. The paired' $t$ ' value of $t=-3.778$ found to be statistically significant at $p<0.001$ level. The Demographic and Obstetrical Variables like age at marriage, previous childbirth and decision maker of family about family planning have shown significant association with Post Test level of Knowledge, Attitude and Acceptance of PPIUCD at $p<0.05$ and $p<0.001$.

Conclusion: The researcher concluded that Prenatal Intensive Counselling increases the mother's Knowledge, Attitude and Acceptance of PPIUCD. So Prenatal Intensive Counselling on PPIUCD can be given to Antenatal Mothers during their antenatal visits to meet the unmet needs of family planning.

\section{Introduction}

Contraception is a method or device used to prevent pregnancy. CuT-380A is an Intrauterine Contraceptive Device provides contraception up to 10 years. In the first year of postpartum period around $65 \%$ of women are having unmet need of family planning. Lack of information, fear of side

\section{More Information}

*Address for Correspondence: Manjubala Dash, Professor in Nursing, HOD, Department of OB \& GY Nursing, Puducherry, India,

Email: manju_narayan@rediffmail.com; shanthinimanikasamy@gmail.com

Submitted: 23 December 2019

Approved: 26 March 2020

Published: 27 March 2020

How to cite this article: Shanthini M, Dash M, Chitra AF, Jayanthi S, Sujatha P. Effectiveness of prenatal intensive counselling on knowledge, attitude and acceptance of post placental intrauterine contraceptive device among mothers Clin J Obstet Gynecol. 2020; 3: 021-025.

\section{DOI: 10.29328/journal.cjog.1001044}

Copyright: @ 2020 Shanthini M, et al. This is an open access article distributed under the Creative Commons Attribution License, which permits unrestricted use, distribution, and reproduction in any medium, provided the original work is properly cited.

Keywords: Post placental intrauterine contraceptive Device; Prenatal intensive counselling

Check for updates

OPEN ACCESS 
maternal deaths and $10 \%$ of child mortality [2-4]. Due to case load of deliveries, the Government of India has introduced Post Placental Intrauterine Contraceptive Device in the National Family Planning Programme since 2012. Selecting the mother and motivating them during antenatal period is an easier task than asking the mother to visit after 6 weeks for insertion of intrauterine contraceptive device [5].

Counselling for postpartum contraception can be given during prenatal care visits or it can be given after birth or both. Postpartum contraceptive counselling during the prenatal period is usually neglected. Contraceptive counselling during routine prenatal care visits, especially in the third trimester according to the needs of couples might increase the use of postpartum contraception [6-8].

In India, approximately $27 \%$ birth occur within 24 months of delivery. Intrauterine contraceptive device is one of the good opinion and most effective method for spacing pregnancies. PPIUCD is not only advantageous to the women and couples; even the service providers benefit from PPIUCD. PPIUCD insertion on the same delivery table saves time and separate clinical procedure is not required [9-11].

The acceptance of PPIUCD is low due to lack of awareness among the staff and the client. Inpite of making contraception widely available, there is poor acceptance of contraception due to ignorance and fear of complications. Inadequate knowledge about contraceptive method and incomplete information about their use are the main reasons for not accepting the family planning $[12,13]$.

\section{Objectives of the study}

To assess the existing level of Knowledge, Attitude and Acceptance of Post Placental Intrauterine Contraceptive Device (PPIUCD) among Antenatal Mothers.

To assess the level of Knowledge, Attitude and Acceptance of Post Placental Intrauterine Contraceptive Device (PPIUCD) among the Mothers after Prenatal Intensive Counselling.

To evaluate the Effectiveness of Prenatal Intensive Counselling on Acceptance of Post Placental Intrauterine Contraceptive Device among Intranasal mothers.

To correlate the Post test Knowledge and Attitude, Knowledge and Acceptance and Attitude and Acceptance among the Mothers.

To associate the Post test level of Knowledge, Attitude and Acceptance of PPIUCD with their selected Demographic and Obstetrical variables.

\section{Methodology}

The Quantitative Pre-experimental One Group Pre and Post Test research design was used to conduct the research at selected hospital, Puducherry. 70 Antenatal mothers were selected by using Purposive sampling for the study who fulfilled the inclusion criteria such as mothers who were primigravida admitted at term pregnancy, multigravida who were not willing for tubectomy, planned for induction, elective caesarean section and willing to participate in the study. The mothers who had multiple pregnancy and who does not know either Tamil or English were excluded from the study. Structured Interview Schedule was used to collect the data. The structured questionnaire comprised of $A, B, C$ and D sections. Section A consist of Demographic and Obstetric Variables. Section B consist of Knowledge questionnaire, Section C comprised of five point likert scale to assess the Attitude of mothers and Section D consist of checklist to assess the Acceptance of PPIUCD. Written and Oral informed consent was obtained from each mother prior to data collection. Pretest was done to all the mothers during antenatal period who were admitted to antenatal ward. Prenatal Intensive Counselling was given on same day after Pretest which comprised of definition, misconception, benefits, mechanism of action, side effects and care after insertion of PPIUCD. The researcher followed up all the mothers who accepted for PPIUCD insertion in labour room and witnessed for insertion of PPIUCD during their intranasal period. The Post Test was carried out with the same tool by using Structured Interview Schedule after $7^{\text {th }}$ day of intervention during postnatal period. The collected data was analyzed by using descriptive and inferential statistics.

\section{Result}

The result showed that majority 42 (60\%) mothers belonged to the age group of 21-25 years, 66 (94.2\%) mothers were Hindus, Graduate and Post Graduate mothers were 33 (47.1\%), 65 (92.9\%) mothers were homemakers, 22 (31.4\%) mothers had family income of less than Rs.5000, 49 (70\%) mothers belonged to joint family, 35 (50\%) mothers married at the age of $15-20$ years, 66 (94.3\%) were prim mothers, $45(64.3 \%)$ mothers said husband is the decision maker of the family, $63(70 \%)$ mothers had no previous history of temporary contraception, 62 (88.6\%) mothers have not adopted to any contraceptive methods, 40 (57.1\%) mothers had previous knowledge of PPIUCD and 25 (35.7\%) mothers said health personnel is the main source of information about PPIUCD (Table 1).

In our study majority of the participants were belong to the age group of 21 to 25 years. Except 2 participants all others had formal education. Nearly $93 \%$ of participants were home maker. None of the participants had more than two children. Only $1 \%$ of participants were used any kind of contraceptive method. Among the participants who were previously heard about the PPICUCD, health personnel were the major source of information.

The post test scores of all parameters studied such as knowledge and Attitude of PPIUCD were higher that pre test 
Table 1: Distribution of Demographic and Obstetrical Variables of Antenatal Mothers. $n=70$ SI.no Demographic and obstetrical variables $\quad$ Frequency $(\mathrm{n}) \quad$ Percentage $(\%)$

\begin{tabular}{|c|c|c|c|}
\hline \multirow[t]{6}{*}{1} & \multicolumn{3}{|l|}{ Age of women } \\
\hline & $15-20$ years & 18 & 25.7 \\
\hline & $21-25$ years & 42 & 60 \\
\hline & $26-30$ years & 9 & 12.9 \\
\hline & 31-35 years & 1 & 1.4 \\
\hline & $36-40$ years & 0 & 0 \\
\hline \multirow[t]{4}{*}{2} & \multicolumn{3}{|l|}{ Religion } \\
\hline & Hindu & 66 & 94.2 \\
\hline & Muslim & 2 & 2.9 \\
\hline & Christian & 2 & 2.9 \\
\hline \multirow[t]{5}{*}{3} & \multicolumn{3}{|l|}{ Educational status } \\
\hline & Illiterate & 2 & 2.9 \\
\hline & Higher secondary education & 23 & 32.9 \\
\hline & High school education & 12 & 17.1 \\
\hline & Graduate and post graduate & 33 & 47.1 \\
\hline \multirow[t]{5}{*}{4} & \multicolumn{3}{|l|}{ Occupation } \\
\hline & Home maker & 65 & 92.9 \\
\hline & Unskilled & 3 & 4.3 \\
\hline & Skilled & 1 & 1.4 \\
\hline & Professional & 1 & 1.4 \\
\hline \multirow[t]{5}{*}{5} & \multicolumn{3}{|l|}{ Family income } \\
\hline & Less than 5000 & 22 & 31.4 \\
\hline & Rs. $5000-80000$ & 15 & 21.4 \\
\hline & Rs. $8000-10000$ & 15 & 21.4 \\
\hline & More than 10000 & 18 & 25.7 \\
\hline \multirow[t]{3}{*}{6} & \multicolumn{3}{|l|}{ Types of family } \\
\hline & Nuclear family & 21 & 30 \\
\hline & Joint family & 49 & 70 \\
\hline \multirow[t]{5}{*}{7} & \multicolumn{3}{|l|}{ Age at marriage } \\
\hline & $15-20$ years & 35 & 50 \\
\hline & $21-25$ years & 31 & 44.3 \\
\hline & $26-30$ years & 4 & 5.7 \\
\hline & $31-35$ years & 0 & 0 \\
\hline \multirow[t]{3}{*}{8} & \multicolumn{3}{|l|}{ Parity } \\
\hline & Primi gravid & 66 & 94.3 \\
\hline & Multi gravid & 4 & 5.7 \\
\hline \multirow[t]{4}{*}{9} & \multicolumn{3}{|l|}{ Number of children } \\
\hline & Nil & 66 & 94.3 \\
\hline & One & 4 & 5.7 \\
\hline & Two & 0 & 0 \\
\hline
\end{tabular}

10 Previous child birth

\begin{tabular}{|l|c|c|} 
Nil & 66 & 94.4 \\
\hline
\end{tabular}

\begin{tabular}{|l|l|l}
\hline Less than 1 year & 1 & 1.4
\end{tabular}

\begin{tabular}{|l|l|l|}
\hline $1-2$ years & 1 & 1.4
\end{tabular}

\begin{tabular}{l|l|l}
$2-4$ years & 1 & 1.4
\end{tabular}

More than 4 years

\begin{tabular}{l|l}
1 & 1.4
\end{tabular}

11 Decision maker in your family for family planning

\begin{tabular}{|l|c|c|}
\hline Husband & 45 & 64.3 \\
\hline Both & 13 & 18.6 \\
\hline Mother in law & 12 & 17.1 \\
\hline Any other & 0 & 0 \\
\hline
\end{tabular}

12 Previous history of temporary contraception

\begin{tabular}{|l|l|l}
\hline Yes & 7 & 30 \\
\hline
\end{tabular}

\begin{tabular}{|l|l|l|}
\hline No & 63 & 70
\end{tabular}

13 Method of adoption

\begin{tabular}{|l|l|l} 
Nil & 62 & 88.6 \\
\hline
\end{tabular}

Oral pills

Condom

Copper T

Any other

14 Previous Knowledge of PPIUCD

\begin{tabular}{|l|l|l|}
\hline Yes & 40 & 57.1 \\
\hline
\end{tabular}

\begin{tabular}{|l|l|l}
\hline No & 30 & 42.9
\end{tabular}

15 Source of information about PPIUCD $(n=40)$

Mass media

Education

Social circle

Health personnel score. This clearly states that Prenatal Intensive Counselling can significantly improve Knowledge, Attitude and Acceptance of PPIUCD (Table 2).

The correlation between Post Test mean score of Knowledge was $14.91 \pm 1.15$ and the Post Test mean score of Attitude was $44.27 \pm 4.70$. The calculated Karl Pearson's correlation value of $r=0.227$ shows positive correlation. This clearly indicates that when the mothers have adequate Knowledge regarding PPIUCD they developed positive Attitude towards PPIUCD. The correlation between Post Test mean score of Attitude was $44.27 \pm 4.70$ and the Post Test mean score of Acceptance was $0.29 \pm 0.455$. The calculated Karl Pearson's correlation value of $r=0.546$ shows positive correlation which was found to be statistically significant at $p<0.001$. This clearly indicates that when the Mothers have positive Attitude towards PPIUCD they were ready to accept for PPIUCD insertion. The correlation between Post Test mean score of Knowledge was $0.29 \pm 0.455$ and the Post Test mean score of Acceptance was $14.91 \pm 1.15$. The calculated Karl Pearson's correlation value of $r=0.103$ shows positive correlation. This clearly indicates that though the Mothers have adequate Knowledge regarding PPIUCD they were not ready to accept for PPIUCD insertion (Table 3).

The Demographic and Obstetrical Variables have not shown significant association with Post Test level of Knowledge. The Demographic and Obstetrical Variables like previous childbirth and age at marriage have shown significant association with Post Test level of Attitude at $p<0.05$ and $p$ $<0.001$. The Variables like decision maker in your family for family planning have shown significant association with Post Test level of Acceptance at $p<0.05$. OtherDemographic and Obstetrical Variables have not shown significant association with Post Test level of Attitude and Acceptance regarding PPIUCD (Table 4).

\section{Discussion}

In this study, the result highlights that majority 56(80\%) mothers had Moderate Knowledge, 9(12.9\%) mothers had Adequate Knowledge and 5(7.1\%) mothers had Inadequate Knowledge. In Pretest level of Attitude majority of 42(60\%) mothers had Positive Attitude, 27(38.6\%) mothers had Neutral Attitude and 1(1.4\%) mother had Negative Attitude. In Pretest majority of $62(89 \%)$ mothers not Accepted and 8(11\%) mothers Accepted for Post Placental Intrauterine Contraceptive Device (PPIUCD) insertion.

The present study was supported by the author Geetha Katheit, (2013) conducted a Prospective Longitudinal Study on "Evaluation of Post Placental Intrauterine Device (PPIUCD) in terms of awareness, acceptance and expulsion in a tertiary care centre" among 503 women counseled 397 women accepted for PPIUCD insertion [14].

Similar study was conducted by Sonali Deshpande, (2017) "Awareness, Acceptability and Clinical Outcome of Post 
Effectiveness of prenatal intensive counselling on knowledge, attitude and acceptance of post placental intrauterine contraceptive device among mothers

Table 2: Comparison of Pre and Post Test level of Knowledge and Attitude regarding Post Placental Intrauterine Contraceptive Device among Mothers. N=70

\begin{tabular}{|c|c|c|c|c|c|c|}
\hline Variables & Mean & Standard Deviation & Median & Min, Max & 'Paired- t' Test & $p$ value \\
\hline Pre-Test level of Knowledge & 9.98 & 2.36 & 10 & 5,16 & \multirow{2}{*}{-20.82} & \multirow{2}{*}{$0.000^{\star \star \star \star}$} \\
\hline Post-Test level of Knowledge & 14.91 & 1.15 & 16 & 13,18 & & \\
\hline Pretest level of Attitude & 34.67 & 5.67 & 35 & 19,48 & -17.25 & $0.000 * \star \star$ \\
\hline
\end{tabular}

Table 3: Correlation of Post Test Knowledge and Attitude, Attitude and Acceptance and Knowledge and Acceptance among Mothers. $n=70$

\begin{tabular}{|c|c|c|c|c|}
\hline Correlation (Post-Test) & Mean & Standard Deviation & $r$ value & $p$ value \\
\hline Level of Knowledge & 14.91 & 1.15 & \multirow{2}{*}{.227} & \multirow{2}{*}{.055} \\
\hline Level of Attitude & 44.27 & 4.70 & & \\
\hline Level of Attitude & 44.27 & 4.70 & \multirow{2}{*}{0.546} & \multirow{2}{*}{$0.000^{* \star \star}$} \\
\hline Acceptance Rate & 0.29 & 0.455 & & \\
\hline Level of Knowledge & 0.29 & 0.455 & \multirow{2}{*}{0.103} & \multirow{2}{*}{0.397} \\
\hline Acceptance Rate & 14.91 & 1.15 & & \\
\hline
\end{tabular}

Table 4: Association of Post Test level of Knowledge, Attitude and Acceptance of Post Placental Intrauterine Contraceptive Device among Mothers with selected Demographic and Obstetrical Variables. $n=70$

\begin{tabular}{|c|c|c|c|c|c|c|c|c|}
\hline \multirow{3}{*}{ SI. no } & \multirow{3}{*}{ Dmographic and obstetrical variables } & \multicolumn{4}{|c|}{ Level of attitude } & \multirow{3}{*}{$\chi^{2}$} & \multirow{3}{*}{ df } & \multirow{3}{*}{$p$ value } \\
\hline & & \multicolumn{2}{|c|}{ neutral } & \multicolumn{2}{|c|}{ positive } & & & \\
\hline & & $n$ & $\%$ & $n$ & $\%$ & & & \\
\hline 1. & \multicolumn{5}{|c|}{ Age at Marriage } & \multirow{5}{*}{7.97} & \multirow{5}{*}{2} & \multirow{5}{*}{$.019 *$} \\
\hline & $15-20$ years & 1 & 2.9 & 34 & 97.1 & & & \\
\hline & $21-25$ years & 0 & 0 & 31 & 100 & & & \\
\hline & $26-30$ years & 0 & 0 & 0 & 0 & & & \\
\hline & $31-35$ years & 1 & 25 & 3 & 75 & & & \\
\hline \multirow[t]{6}{*}{2.} & Previous child birth & & & & & \multirow{6}{*}{34.5} & \multirow{6}{*}{4} & \multirow{6}{*}{$.000 * * *$} \\
\hline & Nil & 1 & 1.5 & 65 & 98.5 & & & \\
\hline & Less than 1 year & 0 & 0 & 1 & 100 & & & \\
\hline & $1-2$ years & 1 & 100 & 0 & 0 & & & \\
\hline & 2-4 years & 0 & 0 & 1 & 100 & & & \\
\hline & More than 4 years & 0 & 0 & 1 & 100 & & & \\
\hline \multirow{3}{*}{ SI.no } & \multirow{3}{*}{ Demographic and obstetrical variables } & \multicolumn{4}{|c|}{ Acceptance } & \multirow{3}{*}{$\chi^{2}$} & \multirow{3}{*}{ df } & \multirow{3}{*}{$p$ value } \\
\hline & & \multicolumn{2}{|c|}{$\begin{array}{c}\text { not } \\
\text { accepted }\end{array}$} & \multicolumn{2}{|c|}{ accepted } & & & \\
\hline & & $\mathbf{n}$ & $\%$ & $\mathbf{n}$ & $\%$ & & & \\
\hline 1. & \multicolumn{5}{|c|}{ Decision maker in your family for family planning } & \multirow{5}{*}{6.85} & \multirow{5}{*}{2} & \multirow{5}{*}{$.032^{\star}$} \\
\hline & Husband & 36 & 80 & 9 & 20 & & & \\
\hline & Both & 9 & 69.2 & 4 & 30.8 & & & \\
\hline & Mother in law & 5 & 41.7 & 7 & 58.3 & & & \\
\hline & Any other & 0 & 0 & 0 & 0 & & & \\
\hline
\end{tabular}

Placental Insertion of Intrauterine Contraceptive Device" among 1944 women visiting antenatal clinic. The result showed that out of 1944 women, only $78(4 \%$ ) of women were aware of PPIUCD. 25\% of women accepted to put PPIUCD and $37 \%$ of women had complications [15].

In Post Test, majority of 69(98.6\%) mothers had Adequate Knowledge and 1(1.4\%) mother had Moderate Knowledge. In Post Test level of Attitude, majority of 68(97.1\%) mothers had Positive Attitude and 2(2.9\%) mothers had Neutral Attitude. In Post Test Acceptance, majority of 50(71\%) mothers not Accepted and 20(29\%) mothers Accepted for Post Placental Intrauterine Contraceptive Device insertion. So when the mothers have Adequate Knowledge and Positive Attitude they were ready to Accept for Post Placental Intrauterine Contraceptive Device insertion (PPIUCD). The present study was supported by the author Putu Ayu Ratna Darmayanti, (2018) conducted a randomized controlled trail on "Difference in Post-Placental Intrauterine Device Acceptance with and without couples Counselling in private practice midwifery clinics, West Denpasar" among 58 pregnant women. The finding showed that 10 women (34.48\%) in control group and 21 women (72.41\%) women in interventional group Accepted to put PPIUCD [16].

The present study was supported by another study conducted by Dr. Serah Wanjiru Ndegwa, (2007) "Effect of Two level of Counselling on Acceptance, uptake and Early Outcomes of the Post Placental Intrauterine Contraceptive Device" among 127 women out of which 64 were given Intensive Counselling and 63 were given routine family planning counseling. The finding showed that $71 \%$ of women accepted for PPIUCD insertion. Continuation rate was 91\%, client satisfaction was $88 \%$ and partner satisfaction was $77 \%$ at 6 weeks [17]. 


\section{Recommendation}

Replication of the study may be done with large samples in different settings to validate and generalize the findings.

Study can also be conducted in community setting.

Effectiveness of Intensive Counselling on Knowledge, Attitude and Acceptance of Post-Partum Intrauterine Contraceptive Device among Postnatal Mothers.

Comparative study between prenatal intensive counselling and routine family counselling on acceptance of Post Placental Intrauterine Contraceptive Device among Mothers.

In present study, the post test scores of all parameters studied such as knowledge and Attitude of PPIUCD were higher that pretest score. This clearly states that Prenatal Intensive Counselling can significantly improve Knowledge, Attitude and Acceptance of PPIUCD. Similar study was supported by the author ManoranjaniGara, (2014) on "Effectiveness of Structured Teaching Programme on PPIUCD among Primigravida Mothers in selected MCH centre, Tripathi" among 55 Primigravida mothers. The finding showed that there was a significant difference between Pre and Posttest level of Knowledge [18].

\section{Conclusion}

The study result revealed that Effectiveness of Prenatal Intensive Counselling on Knowledge, Attitude and Acceptance of Post Placental Intrauterine Contraceptive Device (PPIUCD) among the Mothers. In Post Test the Mothers gained Adequate Knowledge, developed Positive Attitude and Accepted for Post Placental Intrauterine Contraceptive Device insertion. So, Prenatal Intensive Counselling on Post Placental Intrauterine Contraceptive Device can be given to Antenatal Mothers during their antenatal visits to meet the unmet needs of family planning.

\section{References}

1. Shaanthy TK. A cross sectional study on willingness and acceptability: PPIUCD by primipara mothers at a tertiary care hospital, Tamil Nadu, India. Int J Reproductive, Contraceptive, Obstetrics, Gynecol. 2017; 6: 3030-3034.

2. IUCD Reference Manual for MOs and Nursing Personnel; 2013. http:// www.nrhmtn.gov.in/modules/IUCD_Reference_Manual_for_MOs_ and_Nursing_Pwersonne_-Final-Sept_2013.pdf.

3. Chauhan R. Evaluation of acceptability, safety and expulsion of PPIUCD, India. Int J Reproductive, Contraception, Obstetrics, Gynecol. 2018; 3: 1083-1089.
4. Cleland J, Bernstein S, Ezeh A, Faundes A, Glasier A, et al. Family Planning: The unfinished agenda. Lancet. 2006; 368: 1810-1827. PubMed: https://www.ncbi.nlm.nih.gov/pubmed/17113431

5. Janwadkar A. Acceptance, perception, experience and satisfaction of the couple with postpartum intrauterine, contraceptive devices (PPIUCD) insertion, Pune. Asian Pacific J Health Sci. 2016; 3 55-64.

6. Cwiak C, Gellasch T, Zieman M. Peripartum contraceptive attitudes and practices. Contraception. 2004; 70: 383-386.

PubMed: https://www.ncbi.nlm.nih.gov/pubmed/15504377

7. Engin-Ustün $Y$, Ustün $Y$, Cetin $F$, Meydanli MM, Kafkasli A, et al. Effect of postpartum counselling on postpartum contraceptive use. Arch Gynaecol Obstet. 2007; 275: 429-432.

PubMed: https://www.ncbi.nlm.nih.gov/pubmed/17136370

8. Akman M1, Tüzün S, Uzuner A, Başgul A, Kavak Z. The Influence of prenatal counselling on Postpartum contraceptive choice, Turkey. J Int Med Res. 2010; 38: 1243-1249.

PubMed: https://www.ncbi.nlm.nih.gov/pubmed/20925996

9. Nelson A. Intrauterine contraceptive. J Obstet Gynecol. 2008; 6: 219-224.

10. Postpartum IUCD Insertion Manual. Nirman Bhavan, New Delhi 110001: Family Planing Division. Ministry of Health and Family Welfare. Government of India; 2010.

11. Sharma A. A study of awareness and factors affecting Acceptance of PPIUCD in South-East Rajasthan, India. Int J Community Medicine and Public Health. 2017; 4: 2706-2710.

12. Sanskriti P. Post-partum intrauterine device insertion: the unfinished agenda. New Indian J Surg. 2011; 2: 245-247.

13. Bhasin SK, Pant M, Mehta M, Kumar S. Prevalence of usage of different contraceptive methods in East Delhi-a cross sectional study. Indian J Community Med. 2005; 30: 53-5.

14. Katheit G. Evaluation of post-placental intrauterine device (PPIUCD) in terms of awareness, Acceptance and expulsion in a tertiary care centre, Madhya Pradesh. Int J Reproductive, Contraception, Obstetrics, Gynecol. 2013; 2: 539-543.

15. Deshpande S. Awareness, acceptability and clinical outcome of post placental insertion of intrauterine contraceptive device in Marathwada region, India. Indian J Obstetrics, Gynecol Res. 2017; 4: 77-82.

16. Darmayanti PA. Differences in Post Placental Intrauterine Device acceptance with and without couples counselling in private practice midwifery clinics, West Denpasar. Public Health and Preventive Medicine Archive. 2018; 6: 4-9.

17. Ndegwa SW. The effect of two levels of counselling on acceptance, uptake and early outcome of the post placental intrauterine contraceptive device. Nairob. University of Nairob medical library. 2007; $1-30$

18. Gara M. Effectiveness of Structured teaching Programme on PPIUCD (Post Placental Intrauterine Contraceptive Device among Primigravida Mothers in Selected MCH centre, Tirupati, India. Int J Practical Nursing 2014; 2: 87-91. 